\title{
Correspondence
}

\section{Salt-losers and Non Salt-losers in Congenital Adrenal Hyperplasia}

Sirs,

I have read with considerable interest the article by Galal, Rudd, and Drayer on Congenital Hyperplasia which appeared in the August issue on page 410. I would like to commend the authors for their ingenious use of the 'index' for 21-hydroxylation in vivo, but to take exception to their conclusions.

The authors note that, in response to ACTH, non salt-losers produce more 17-hydroxycorticosteroids relative to pregnanetriol than do the salt-losers. They then conclude that genetic factors responsible for cortisol production on the one hand, and aldosterone production on the other, are closely related.

I would like to suggest that apart from a common genetic defect in production of enzymes inducing 21-hydroxylation of 17-hydroxyprogesterone, the two 'classical' groups-salt-losers and non salt-losers-are genetically quite distinct.

The salt-losing patient presumably loses salt for two reasons: he cannot produce aldosterone (Bryan, Kliman, and Bartter, 1965) in the adrenal zona glomerulosa, and he produces greatly excessive amounts of progesterone and 17-hydroxyprogesterone in the zona fasciculata. The last-named steroids have been shown to have the property of inducing salt loss, albeit weakly. Whereas the syndrome may be explained in both groups as the result of a defect in 21-hydroxylation of 17hydroxyprogesterone, this defect alone will not explain a failure of 21-hydroxylation of progesterone, precursor to 17-hydroxyprogesterone, an hydroxylation which is required for the production of desoxycorticosterone and aldosterone (see Figure).

Biogenetic Pathways for Aldosterone and Cortisol

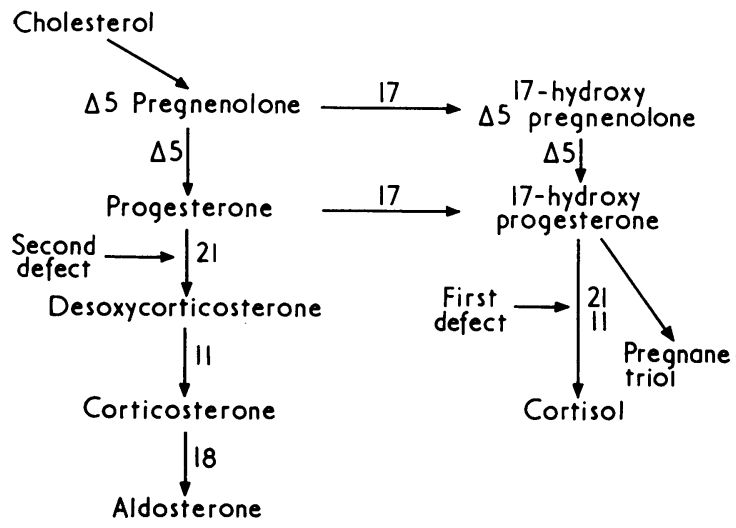

Numbers refer to isomerase $(\Delta 5)$ or hydroxylation sites $(17$, etc.).

In the non salt-losers, indeed, only the first defect is found. Aldosterone production, not limited by an enzymatic block, rises to very high values (Bartter, Henkin, and Bryan, 1968). The cause of this secondary aldosteronism is presumably the tendency to salt loss induced by the same salt-losing steroids; a result appears to be the effective prevention of actual salt loss. As the overproduction of aldosterone is secondary, it is never associated with hypertension, hypokalaemia, or alkalosis.

In one reported instance (Visser and Degenhart, 1968), salt loss occurred despite normal secretion of aldosterone: genetically, this patient clearly belonged to the non salt-losing variety. We are aware of no report, however, in which true salt-losers who cannot produce aldosterone, presumably because of the defect of 21hydroxylation in the zona glomerulosa, are found in the same family with non salt-losers, in whom the zona glomerulosa produces 21-hydroxylated steroids (including aldosterone) in excess. This has led us to postulate (Bartter et al., 1968) that the enzymes specific for the two substrates are either entirely separate enzymes, or are iso-enzymes under different genetic control.

\section{Frederic C. BartTer \\ Endocrinology Branch, National Heart Institute, Bethesda, Maryland 20014, U.S.A.}

\section{REFERENCES}

Bartter, F. C., Henkin, R. I., and Bryan, G. T. (1968). F. clin. Invest., 47, 1742.

Bryan, G. T., Kliman, B., and Bartter, F. C. (1965). ibid., 44, 957. Visser, H. K. A., and Degenhart, H. J. (1968). Acta paediat scand., 56, 216.

This letter was shown to Dr. B. T. Rudd who writes:

I am very grateful to Dr. Bartter for his provocative comments on our paper. However, the matters he sets forth are somewhat controversial and as yet not entirely clear. First of all there is at present no definitive demonstration of a truly salt-losing steroid, though one may certainly exist and be produced in excessive quantities in congenital adrenal hyperplasia. We are aware of Dr. Bartter's contribution which appeared in print after our manuscript had been accepted for publication. We did not address ourselves directly to the matter of aldosterone in our studies. From the 